\title{
VERBOS TRANSITIVOS CON ADJETIVO VERBAL: UNA CONSTRUCCIÓN «DORMIDA»*
}

\author{
JosSE DE KOCK
}

\section{EN 19 TEXTOS}

En español, como en otras lenguas románicas, el adjetivo verbal conjugado con ser concuerda en género y número con el regente, formando así la voz pasiva, en la que el regente del verbo conjugado designa al paciente $u$ objeto de la acción expresada por el adjetivo verbal. Ser es el verbo más frecuente en esta función (153 ejemplos en el corpus de 19 textos), pero otros verbos intransitivos, empleados intransitivamente o transitivos pero conjugados en forma pronominal (estar, quedar, verse, etc.), pueden desempeñar el mismo papel. El español se destaca de otras lenguas emparentadas por recurrir más a menudo a un número mayor de verbos diferentes. En un corpus como el de 19 textos hay hasta 27 verbos distintos en 332 ejemplos ${ }^{1}$, que están construidos con un adjetivo verbal en las mismas condiciones que ser.

En todos los casos el regente designa al paciente u objeto de la acción expresada por el adjetivo verbal. Con respecto a ser, verbo neutro que se limita a traspasar la acción expresada por el adjetivo verbal al regente, el recurso a otros verbos permite matizar la relación actancial al añadirle el sentido específico que tales verbos tienen. La posibilidad de enriquecer o variar la expresión actancial puede dar lugar a distinciones muy sutiles cuando el significado de los verbos contrincantes es próximo; es lo que ocurre con estar en relación con ser.

\footnotetext{
* Estudio realizado en el marco de J. De Kock, Gramática española: Enseñanza e investigación, Ediciones Universidad de Salamanca, Salamanca, 1990 ss, de ahora en adelante GE.EI, para el t. II.6, Norma, libertad y probabilidad. Ocho soluciones del español, en preparación. El corpus utilizado aquí se constituye de 19 textos, GE.EI, t.III.1 (1. a reimpresión, 1996) y 20 textos, GE.EI, t.III.2 (1992). Las referencias y la terminología son las de GE.EI.

1 Véanse más detalles sobre la construcción de verbo intransitivo con adjetivo verbal y los ejemplos en 19 textos en GE.EI, t. II.3, La noción de auxiliaridad, passim.
} 


\begin{tabular}{lrlr}
\hline ser & 153 & arribar & 2 \\
estar & 77 & hallarse & 2 \\
quedar & 22 & seguir & 2 \\
verse & 11 & continuar & 1 \\
ir & 10 & creerse & 1 \\
parecer & 8 & decirse & 1 \\
sentirse & 7 & entenderse & 1 \\
vivir & 6 & existir & 1 \\
encontrarse & 5 & mostrarse & 1 \\
permanecer & 4 & pasar & 1 \\
salir & 3 & rodar & 1 \\
andar & 3 & volver & 1 \\
considerarse & 3 & & 332 \\
resultar & 3 & & \\
aparecer & 3 & total &
\end{tabular}

El adjetivo verbal puede' también estar asociado con haber, así como verbos transitivos como tener, por ejemplo. En el corpus de 19 textos se encuentran en esta construcción, además de tener: dejar, ver, llevar, mantener, devolver, encontrar y traer.

(...) los historiadores han reconocido la particularísima importancia de ese reinado. AYA 402

Tengo entendido que también el consenso de otros lectores (...) es el mismo de Azorín y de Maeztu, (...) MAR 117

(...) querían cotejar sus afinidades o dejar sentadas sus diferencias, (...) BEN 78

(...) ellos comienzan a ver cumplida en nosotros una realidad vislumbrada por (...) CAR 456

El hecho de que una palabra exista no lleva aparejada la suposición de que (...) CEL 502

Mientras el pluralismo mantenía desparramado el poder de Francia, (...) ORT 472

(...) si se tomara la inútil molestia de repasar viejos números de la revista (...) encontraría publicado en ella, hacia 1930, el texto de una conferencia (...) AYA 179

(...) contestaríamos esa pregunta devolviéndola invertida: GAL 123

(...) la institución armada del vasallaje a que la traían sometida aquellos jefes guerreros (...) GAL 353

El conjunto de los verbos que se construyen de este modo no es, sin embargo, comparable a la serie de verbos intransitivos, y ello por numerosas razones: gramaticales, semánticas y cuantitativas, concomitantes todas ellas.

En los ejemplos citados, haber y los demás verbos sólo tienen en común la posición respectiva del adjetivo verbal, de la forma conjugada y del régimen. No puede ser de otro modo cuando este último es un pronombre personal átono, un pronombre relativo, una oración completiva (sustantiva) o un 
infinitivo ${ }^{2}$. En tal caso, no cabe variación en cuanto al lugar respectivo de las formas a las que se ha recurrido, sea cual sea el verbo conjugado.

(...) una descalificación del hombre que pretende dejarle reducido a aquello que el hombre tiene en común con los objetos (...) MAC 214

(...) contestaríamos esa pregunta devolviéndola invertida: GAL 123

El carácter vertical de las estructuras nacionales europeas, que mientras se van transformando las mantiene articuladas en dos pisos.(..) ORT 140

(...) para que no desfallezca la fe que tiene puesta en el ejercicio cabal de la soberanía. GAL 176

Tengo entendido que también el consumo de los lectores cultos (...) MAR 117

En cambio la situación es diferente cuando el régimen es un sustantivo. Mientras que haber y el adjetivo verbal están soldados hasta tal punto que es imposible separarlos o invertirlos, con cualquier otro verbo se puede insertar el régimen directo entre los dos.

(...) tanto más se pertenece uno a sí mismo cuanto más tenga su pensamiento y su voluntad, su vida toda, puesta al servicio que hoy venimos a realizar, (...) GAL 29

Tales inserciones rompen, o cuando menos relajan el nexo entre el adjetivo verbal y el verbo conjugado. La dislocación puede resultar acentuada si la construcción se prolonga, por ejemplo, mediante un régimen preposicional. La independencia del adjetivo verbal con respecto al verbo conjugado es patente cuando se trata de un régimen introducido por por, complemento de agente, incompatible con una construcción activa.

Si hemos de darle la realidad exigida por su existencia, (...) CAS 444

A veces se transluce en la puntuación:

de haber llevado hasta sus penúltimas consecuencias el criterio de entonces, en el diccionario tendríamos, alojados con no desigual naturalidad, tres o cuatro nuevas letras: CEL 859

El verbo conjugado y el adjetivo verbal también pueden ir separados por locuciones adverbiales con referencia a uno u otro, según el caso. Con $h a-$ ber el adverbio se refiere al conjunto por lo que se encuentra casi siempre detrás del adjetivo verbal o delante del verbo conjugado.

\footnotetext{
${ }^{2}$ En el corpus no hay ningún ejemplo con infinitivo en el que el adjetivo verbal esté inmediatamente pospuesto al verbo; un ejemplo con locución adverbial insertada es el siguiente:

Tengo a mi vez resuelto inhibirme por completo de cuanto pueda inscribirse en arte semejante. FER 665.
} 
Salvador de Madariaga ha descrito claramente la situación económica en España (...) CAS 268

(...) la mente hispánica siempre ha dejado ciertas filtraciones a la libertad (...) REY 242

Creo, eso sí, que Borges tiene desde ya asegurados dos lugares de excepción: BEN 176

(...) los estrechos límites de minoridad social (...) a los que la (..) comunidad de los varones las tiene tradicionalmente destinadas. FER 716

(...) con lo cual llego a un pensamiento (...) que me interesa dejar aquí someramente formulado, (...) ORT 145

Adverbio y régimen pueden estar insertados juntos.

Desde que el Gran Almirante (...) viese el continente nuevamente descubierto como un remedio universal (...) CAR 426

Aquí se termina el parecido - forzoso de tratarse de regímenes pronominales, por ejemplo, y ocasional si es un sustantivo- entre haber y los otros verbos. Todo lo demás es diferente. La concordancia en género y número del adjetivo verbal con el régimen directo, que se efectúa con todos los verbos excepto con haber, constituye la divergencia más destacada.

todos ellos mantendrán garantizada su existencia, verán respetados sus derechos, (...) GAL 268, 269

Un consenso universal ha condenado nuestra conquista americana. CAS 127

Con excepción de haber todos los verbos observados pueden construirse con régimen directo; su comportamiento es el de verbos independientes, mientras que haber tiene siempre función instrumental.

La vetada voz a que vengo aludiendo tiene una ilustre etimología (...) CEL 412

(...) la mente hispánica siempre ha dejado ciertas filtraciones a la libertad (...) REY 242

Mientras que los otros verbos se construyen igualmente con adjetivo calificativo ${ }^{3}$, haber sólo puede hacerlo con adjetivos de raíz verbal; su cometido instrumental se limita al área verbal.

\footnotetext{
${ }^{3}$ Muchas veces es dificil distinguir, como también con un verbo intransitivo, entre adjetivo verbal y calificativo. Para no excluir indebidamente ejemplos de una construcción poco frecuente, se ha considerado verbal cualquier forma en -a(i)do a la cual corresponde un infinitivo, salvo si existe una clara indicación contextual en contra. De ahí que embridado y merecido se hayan tenido en cuenta.

como tampoco el que se lo vitupere por su libertad de pensamiento - casi nunca por llevarlo embridado - . MAR 165

(...) [el artista] tendrá la consideración merecida, (...) SAL 438
} 


\begin{abstract}
Hasta Echeverría (...) aconsejaba una democracia no "ultrademocrática" cuando no la teníamos sino despótica. MAR 385

Ocuparon las funciones que dejaba vacantes a este respecto, Francia, Holanda y Inglaterra (...) CAS 283

Esta acepción que propugno puede encontrarla viva cualquier paseante por las ciudades de España, (...) CEL 531

Porque el señoritismo lleva implicita una estimativa errónea y servil, (...) MAC 71

hay una condición suprema del progreso moral y mental - la cual está por entero dentro del poder del hombre mismo ponerla en práctica y mantenerla intangible- (...) PER 198
\end{abstract}

Tampoco desde el punto de vista semántico se parecen las construcciones con adjetivo verbal y haber y estas mismas con otros verbos transitivos. Aunque el actante designado por el régimen directo sea paciente $u$ objeto de la acción expresada por el adjetivo verbal, la construcción con haber ha perdido su significado actancial y sólo lo tiene de tiempo; incluye una porción variable de pasado en el área temporal designada por el verbo conjugado; con los otros verbos la relación actancial se mantiene y el tiempo del conjunto agregado es el de la forma conjugada. Esto explica que con haber, al revés de lo que ocurre con los otros verbos, pueda no haber régimen, que el adjetivo verbal no concuerde con este, que no pueda asociarse con adjetivos calificativos y que pueda haber adjetivos verbales de verbos transitivos o intransitivos. En cualquier caso, haber carece de sentido propio.

Los otros verbos, al contrario, marcan explícitamente mediante la concordancia la relación actancial entre el adjetivo verbal y el régimen directo, se refieren al momento enunciado por la forma conjugada y su sentido matiza la acción expresada por el adjetivo verbal.

Algunos verbos, sin embargo, parecen prestarse a interpretaciones divergentes. En los ejemplos con tener, verbo cuyo significado es el más próximo del original de haber, la diferencia de significado no siempre salta a la vista; el parentesco semántico propicia la amalgama. Tener, en el ejemplo siguiente de Jiménez, no parece dar lugar a un significado más específico que haber, con el mismo adjetivo verbal, en el ejemplo de Machado, sino lo contrario, y, de modo similar, aparenta incluir anterioridad en la acción expresada.

(...) cuando la contienda no habia aún perdido su aspecto de mera guerra civil, (...) MAC 33

Unamuno, ampliando a su vez, y a la vez que Darío, la trascendencia de Bécquer, (...) nos sacude, nos escita con la elevada inquietud metafisica, el poder interior, el «acento» (...) que teníamos perdido casi también desde Bécquer y que había dado antes autenticidad perdurable a la lírica española individual, (...) JIM 46 
Cabe preguntarse hasta qué punto teníamos perdido podría ser una mera variante estilística, en paralelo con había dado de la oración relativa coordinada que sigue, en el ejemplo citado de Jiménez, como tengo puesta y he manifestado en el ejemplo siguiente de Gallegos ${ }^{4}$.

Yo he manifestado ya varias veces en el seno de mi partido la confianza inconmovible que tengo puesta en el sector obrero sindicalizado de nuestra organización. GAL 702

En otros momentos se tiene la impresión de un cruce entre el pretérito perfecto compuesto y el presente: la fe que [el pueblo] tiene puesta es, a la vez, la fe que [desde el memorable 27 de octubre de 1946] ha puesto y la fe que tiene [en 1947].

Los enemigos de este régimen de derecho y libertad, que nunca se resignarán a que se les haya arrebatado el privilegio de suplantar la voluntad popular con la desaforada suya, vigilan y esperan la mínima oportunidad propicia para la manotada de recuperación y es necesario que el pueblo de Venezuela les quite de la cabeza toda pretensión de reconquista, demostrándoles, con intachable compostura cívica, como en el memorable 27 de octubre de 1946, que está en posesión consciente y serena de su derecho fundamental. Que no necesita estimulantes de improperios contra el adversario para que no desfallezca la fe que tiene puesta en el ejercicio cabal de su soberanía. GAL 176

En los demás ejemplos, tener no es, bajo ningún concepto, un equivalente de haber.

Tengo entendido que también el consenso de otros lectores cultos españoles que nos conocen bien es el mismo de Azorín y de Maeztu, (...) MAR 117

Tampoco está fuera de dudas que dejar goce de su pleno valor léxico en asociación con dicho en el ejemplo siguiente.

Dado que la sinonimia absoluta, como ya dejé dicho, no se presenta (...) CEL 676

Es de observar, sin embargo, que dos de seis ejemplos con dejar están combinados con dicho y otros dos con un adjetivo verbal cuya combinación se incluye en el mismo campo semántico (apuntado, sentado). La pérdida de significado de dejar - si es que la hay - proviene de la lexicalización de la secuencia, lo contrario de la gramaticalización.

(...) las ofrezco, como dejé apuntado, no en el artículo de cada voz eje sino en el de cada raíz (...) CEL 772

Eran simplemente lectores (...) que querían cotejar sus afinidades o dejar sentadas sus diferencias, (...) BEN 78

\footnotetext{
${ }^{4}$ Ello recuerda la alternancia de subjuntivos imperfectos en -ra y -se en el mismo texto; véase GE.EI, t. I.2, Índices y concordancias en la clase de gramática (...): $\S 1$, La concurrencia de subjuntivos en "-ra" y "-se", en coordinación o yuxtaposición.
} 
No es seguro que Cela, propenso a la construción con verbo transitivo, haya querido expresar con dejar otra cosa que Ferlosio - que no recurre a ella- con haber en unión con los mismos adjetivos verbales.

En ellos debe de ocurrir, sin duda alguna (aunque de bien distinto modo $\mathrm{y}$, como ya he apuntado, no, ciertamente, por error, sino por expreso deseo de autores y empresarios), (...) FER 228

ella no ha hecho más que tolerar, y, como ya he dicho más arriba, considero perfectamente inútil (...) cualquier empeño por su parte de mediar en ello, (...) FER 333

Con otros adjetivos verbales el sentido de dejar no se debilita.

El hombre masa no existe; las masas humanas son una invención de la burguesía (...), basada en una descalificación del hombre que pretende dejarle reducido a aquello que el hombre tiene en común con los objetos del mundo físico: MAC 214

En el corpus de 19 textos, ocho verbos transitivos, en 27 ejemplos, están acompañados de un adjetivo verbal, en apariencia, en las mismas condiciones morfosintácticas que haber, exceptuando la concordancia con el régimen. En el 59 por ciento de los ejemplos el régimen es un pronombre personal o relativo o una oración completiva cuya posición en la frase no varía, por razones específicas. De tal suerte sólo quedan 11 ejemplos con régimen sustantivo pegados libremente al verbo conjugado; se reparten entre siete verbos diferentes: ver (3 ejemplos), dejar (2), llevar (2), mantener (2) encontrar (1) y tener. Si se suman unos y otros se obtiene: tener (8), dejar (6), ver (4), llevar (3), mantener (3), devolver, (1), encontrar (1), juzgar (1) y traer (1) 5 .

\footnotetext{
${ }^{5}$ Es conveniente no olvidar que se trata de frecuencias máximas; por diversos motivos se podrían rechazar varios de los ejemplos contados. El ejemplo de Cela en el que el adjetivo verbal está separado del verbo conjugado por una coma:

(...) en el diccionario tendríamos, alojadas con no desigual naturalidad, tres o cuatro nuevas letras: CEL 860 ,

el ejemplo de Jiménez con el adjetivo verbal acompañado de un complemento con por, que se puede interpretar como complemento agente:

(...) la [vida] tenemos determinada por una fija espera; JIM 644,

o aquellos en los que aparece como dejar dicho (apuntado), entre comas y que, en sentido estricto, no tienen régimen.

Dado que la sinonimia absoluta, como ya dejé dicho, no se presenta (...) CEL 676 (...) las ofrezco, como ya dejé apuntado, no en el artículo de cada voz sino (...) CEL 772
} 


\begin{tabular}{lrrr}
\hline & + sustantivo & otros & total \\
\hline tener & 1 & 7 & 8 \\
dejar & 2 & 4 & 6 \\
ver & $* 3$ & 1 & 4 \\
llevar & 2 & 1 & 3 \\
mantener & 2 & 1 & 3 \\
devolver & 0 & 1 & 1 \\
encontrar & 1 & 0 & 1 \\
juzgar & 0 & 1 & 1 \\
traer & 0 & 1 & 1 \\
total & 11 & 16 & 27 \\
\hline
\end{tabular}

Obsérvese, además, que más de la mitad de los 27 ejemplos provienen sólo de dos autores: Gallegos (8 ejemplos) y Cela (6). No aparece la construcción en ocho textos. Ambas características, acumulación en unos y ausencia en otros, ponen en tela de juicio la índole general de la asociación.

Mientras que haber se construye, en su mayoría, con adjetivo verbal (602 ejemplos de 929, los otros son construcciones con infinitivo o formas impersonales) y no tiene nunca empleo como lexema, los demás verbos se construyen así sólo ocasionalmente y siguen siendo utilizados independientemente mucho más que asociados a un adjetivo verbal.

\begin{tabular}{lrr}
\hline & total & + adj. verbal \\
\hline haber & 929 & 602 \\
tener & 314 & 8 \\
dejar & 76 & 6 \\
ver & 108 & 4 \\
llevar & 60 & 3 \\
mantener & 15 & 3 \\
devolver & 3 & 1 \\
encontrar & 59 & 1 \\
juzgar & 17 & 1 \\
traer & 30 & 1 \\
\hline
\end{tabular}

En el caso de construccciones poco frecuentes, sin estabilizar y complejas - circunstancias que concurren - nos parece prudente incluir el máximo de ejemplos a fin de no restar importancia al problema planteado.

Tampoco es indiscutible la incorporación de ejemplos con un pronombre personal, relativo, un infinitivo o una oración completiva (17 ejemplos de 28), puesto que se carece de alternativa. Mientras que se ha tenido en cuenta el primero de los ejemplos siguientes, el último, aun siendo del mismo autor, se ha excluido.

(...) la fe que [el pueblo] tiene puesta en el ejercicio cabal de su soberanía. GAL 176 (...) se pertenece uno a sí mismo cuanto más tenga su pensamiento y su voluntad, su vida toda, puesta al servicio que hoy venimos a realizar, (...) GAL 28 
El número de verbos transitivos diferentes unidos a un adjetivo verbal en el corpus de 19 textos es sólo de ocho frente a 27 verbos intransitivos. La distribución del número de ejemplos con cada verbo es también muy distinta: mientras que haber es muy frecuente -incluso mucho más que el más frecuente de los verbos intransitivos (ser) - , los demás verbos sólo aparecen muy pocas veces: haber alcanza el 96 por ciento de los ejemplos transitivos, ser el 46 por ciento; mientras que estar, el segundo por su frecuencia, alcanza el 23 por ciento de los ejemplos, tener tan sólo llega al uno por ciento. La competencia entre verbos en cada serie no es equiparable. Sea cual sea el estatuto gramatical de estar, tener no se le puede ni comparar; y otro tanto ocurre con los otros verbos.

\begin{tabular}{|c|c|c|c|c|c|}
\hline & + A. V. & $\%$ & & + A. V. & $\%$ \\
\hline haber & 602 & 95,71 & ser & 153 & 46,08 \\
\hline tener & 8 & 1,27 & 'estar & 77 & 23,19 \\
\hline dejar & 6 & 0,95 & quedar & 22 & 6,62 \\
\hline ver & 4 & 0,64 & verse & 11 & 3,31 \\
\hline llevar & 3 & 0,48 & ir & 10 & 3,01 \\
\hline mantener & 3 & 0,48 & parecer & 8 & 2,40 \\
\hline devolver & 1 & 0,16 & sentirse & 7 & 2,10 \\
\hline encontrar & 1 & 0,16 & vivir & 6 & 1,80 \\
\hline juzgar & 1 & 0,16 & encontrarse & 5 & 1,50 \\
\hline \multirow[t]{2}{*}{ traer } & 1 & 0,16 & permanecer & 4 & 1,20 \\
\hline & & & salir & 3 & 0,90 \\
\hline \multirow[t]{17}{*}{ total } & 629 & & andar & 3 & 0,90 \\
\hline & & & considerarse & 3 & 0,90 \\
\hline & & & resultar & 3 & 0,90 \\
\hline & & & aparecer & 2 & 0,60 \\
\hline & & & arribar & 2 & 0,60 \\
\hline & & & hallarse & 2 & 0,60 \\
\hline & & & seguir & 2 & 0,60 \\
\hline & & & continuar & 1 & 0,30 \\
\hline & & & creerse & 1 & 0,30 \\
\hline & & & decirse & 1 & 0,30 \\
\hline & & & entenderse & 1 & 0,30 \\
\hline & & & existir & 1 & 0,30 \\
\hline & & & mostrarse & 1 & 0,30 \\
\hline & & & pasar & 1 & 0,30 \\
\hline & & & rodar & 1 & 0,30 \\
\hline & & & volver & 1 & 0,30 \\
\hline & & & total & 332 & \\
\hline
\end{tabular}

A favor de tan elevada tasa de empleo, la construcción con haber se ha gramaticalizado por completo; haber se ha convertido en una forma instrumental (morfema), comúnmente llamada auxiliar. Los otros verbos se em- 
plean insuficientemente en las mismas condiciones para poder alcanzar un estatuto similar; las diferencias de comportamiento que ello conlleva lo atestiguan. La consecuencia es que el adjetivo verbal no es en realidad el núcleo verbal sino más bien el atributo del grupo nominal, pero sin que éste llegue a ser exclusivamente el régimen del verbo conjugado.

Aparte de las obligaciones que impone la naturaleza morfosintáctica del régimen, la secuencia que consta de un verbo transitivo y de un adjetivo verbal concordante es una asociación libre con posibilidad de múltiples variaciones. La anticipación del adjetivo verbal con respecto al régimen y su proximidad con el verbo conjugado en un pequeño número de casos parece indicar que hay o ha habido un paso hacia la gramaticalización, pero que no ha desembocado en nada en español moderno. El empobrecimiento de la carga semántica unido a la incorporación de la noción de anterioridad análogamente a lo que se observa con haber, en unos pocos casos, que a su vez son discutibles y se producen sólo con los dos verbos más frecuentes (tener y dejar), son una muestra de la misma tentativa y de su fracaso. La lengua no ha dado lugar a una fórmula que exprese con prioridad la relación actancial entre el régimen y el adjetivo verbal, comparable en importancia a la construcción pasiva a la que incumbe expresar esa misma relación entre el adjetivo verbal y el regente ${ }^{6}$.

\section{SEGÚN LA TRADICIÓN}

A raíz de los resultados en el corpus examinado no parece adecuado calificar tener, ni ningún otro verbo transitivo asociado a un adjetivo verbal, de auxiliar al igual que haber, como lo hace Bello, por ejemplo.

«En lugar del auxiliar haber combinado con el participio sustantivado, se usan también, aunque mucho menos frecuentemente, formas compuestas en que el verbo tener hace el oficio de auxiliar, y se combina con el participio adjetivo: Tengo, tuve, tendré, tenía, tendría, escrita la carta. El significado temporal de estas frases se ajusta a las mismas reglas que en las que se componen con haber. El verbo tener lleva comúnmente en

\footnotetext{
${ }^{6}$ La experiencia muestra que, en el estado actual de la lengua, el utilizador concibe e incluso percibe mal la relación actancial entre el adjetivo verbal y el régimen. Esto podría achacarse al carácter híbrido de la construcción, puesto que combina, de hecho, dos formas verbales orientadas diferentemente: la primera concuerda con el regente mientras que la segunda lo hace con el régimen. Esto no es incompatible en sí, como tampoco plantearía ningún problema si no fuera porque con verbo intransitivo ambas formas verbales concuerdan con el regente y con haber, al quedar neutralizada la concordancia del adjetivo verbal no parece que surja una orientación diferente. Ello explica, quizás, que con haber la concordancia con el régimen directo no haya sido nunca la regla en español antiguo y que se haya abandonado con tanta facilidad cuando la primacía de la actancia ha cedido el paso a la expresión del tiempo.
} 
ellas un complemento acusativo a cuyo término sirve de predicado al participio. Pero este acusativo es a veces tácito e indeterminado.» ${ }^{7}$

Por antigua que sea la opinión de Bello es la que se sigue recogiendo hoy en día en numerosos y excelentes manuales españoles y extranjeros; por M. Moliner o, sin más comentarios, por Butt y Benjamin, por ejemplo,

[tener] «hace de auxiliar con el mismo significado que "haber", poniendo cierto énfasis en la expresión; (...): Te lo tengo dicho muchas veces. Me tenía preparada una sorpresa. Me tiene hechos muchos favores. Tenme preparada la comida para las dos.» ${ }^{8}$

"Tener is occasionally used as an auxiliary to denote the successful acquisition of some object or the fulfilment of some task.» ${ }^{9}$

No parece justificado citar los mismos verbos mezclados con verbos intransitivos asociados a un adjetivo verbal, como ocurre en el Esbozo de una nueva gramática de la lengua española:

«Los verbos llevar, tener, estar y ser y a veces traer, quedar y dejar, forman perífrasis verbales como verbos auxiliares, desposeídos por lo tanto de su significado propio.» 10

Tampoco parecen aceptables actitudes ambiguas o contradictorias como traslucen en más de un manual de gramática. En el Manual de gramática española de Seco, por ejemplo, tener figura unas veces entre estar, ir y venir como auxiliar, pero se descarta como tal en otro lugar.

«Los verbos auxiliares más comunes son haber y ser, aunque también se emplean como tales con carácter especial los verbos estar, tener, ir, venir, etc. ${ }^{11}$ «Suelen indicarse como expresiones perifrásticas las formadas por tener y un participio pasado: Yo tengo escrito un drama. Sin embargo, en realidad, la frase no parece tener otro sentido nuevo que el que le presta la presencia del participio adjetivo escrito, complemento predicativo en la oración.» ${ }^{12}$

Concluir, como lo hace M. Moliner, que tener y haber son equivalentes, basándose únicamente en la yuxtaposición del adjetivo verbal y del régimen: «un complejo verbal, tiene alquilado semejante a 'ha alquilado'» ${ }^{13}$, o que dejar es auxiliar, a raíz de una interpretación semántica subjetiva: «Se

\footnotetext{
${ }^{7}$ A. Bello, Gramática de la lengua castellana, ed. R. Trujillo, Santa Cruz de Tenerife, $1981, \S 708$.

${ }^{8}$ M. Moliner, Diccionario de uso del español, Madrid, 1975, t. II, pág. 1.287 b.

9 J. Butt y C. Benjamin, A new reference Grammar of Modern Spanish, 2." ed. Londres, 1994, § 14.6.3.

${ }^{10}$ Real Academia Española, Esbozo de una nueva gramática de la lengua española, Madrid, 1973, § 3.12.6.b.

11 R. Seco, Manual de gramática española, revisado y ampliado por M. Seco, Madrid, $1982, \S 43$.

12 Idem, § 140.

${ }^{13}$ M. Moliner, Diccionario de uso del español, op. cit., t II, pág. 1.287 a.
} 
considera "dejar" cuando acompaña a otro verbo como verbo auxiliar, salvo en casos en que patentemente le corresponde a él la esencia del significado de la frase» ${ }^{14}$ parece bastante precipitado y es hacer caso omiso de otras diferencias, que aun cuando menos llamativas son fundamentales.

El análisis del corpus confirma, en cambio, la conclusión a la que llega Hernández Alonso:

«(...) ofrece grandes dificultades interpretar tales grupos como perífrasis verbales. En casos como me tiene aburrido o llevo leidos tres capitulos, etc., no podemos hablar de perífrasis, sino de dos unidades funcionales, el verbo en forma flexiva y el participio atributo del complemento.» 15

Lo que es cierto, pero que había que demostrar.

Importa poco, en tales condiciones, saber qué verbos hay que citar y en qué orden, tanto la lista como el orden varían de un comentario a otro y las más de las veces se termina por etc. Parece establecido que tener es el más frecuente de ellos, pero su frecuencia y la diferencia de frecuencia con los verbos que le siguen son tan reducidas que carecen de significado. Queda claro, por otro lado, que con cada nuevo corpus surgen otros verbos.

\subsection{EN 20 TEXTOS}

Para controlar hasta qué punto es representativa la lista de ejemplos que procede de 19 textos, se ha explorado sistemáticamente con los mismos criterios el corpus paralelo de 20 textos.

En este corpus, 12 verbos transitivos, distintos de haber, están asociados a un adjetivo verbal en 16 ejemplos, frente a ocho en 27 ejemplos en 19 textos ${ }^{16}$. Cinco verbos (tener, dejar, ver, llevar y devolver) son comunes a ambos corpus. Tres verbos presentes en 19 textos no aparecen en 20 textos (mantener, encontrar, traer); con otros siete ocurre lo contrario (considerar, dar, sacar, estimar, juzgar, llamar, creer). Con excepción de mantener ninguno de éstos da lugar a más de un ejemplo. En nueve de los 20 textos no hay ningún ejemplo, como tampoco en ocho de 19 textos.

En la mayoría de los ejemplos de 20 textos (el 56 por ciento), como en 19 textos, el régimen es un pronombre personal o relativo, cuya posición no es variable. Sólo con tener, dejar, ver (verbos comunes), considerar, dar y sacar se encuentra un sustantivo régimen (seis casos). La secuencia dejar dicho se encuentra también en el corpus de 20 textos.

14 Idem, t. I, pág. 878 b.

15 C. Hernández Alonso, Gramática funcional del español, Madrid, 1986, pág. 391.

16 El número más elevado de ejemplos en el corpus de 19 textos se debe a que se hallan incluidos dos autores visiblemente adictos a la construcción en los textos recogidos: 15 de los 28 ejemplos. Este tipo de acumulaciones tienen tanto mayor impacto cuanto el número total de ejemplos es pequeño. 
Al contrario de haber, que nunca es lexema, los demás verbos suelen ser independientes y sólo pocas veces se encuentran asociados a un adjetivo verbal, tanto en 20 textos como en 19 textos. En las mismas condiciones haber alcanza el 98 por ciento de los ejemplos -96 por ciento en 19 textos- y tener, por ejemplo, el 0,41 por ciento -el 1,27 por ciento en 19 textos-. La diferencia entre haber y los demás verbos es igualmente grande en ambos corpus e incluso mayor en el corpus paralelo.

Algunos ejemplos del corpus de 20 textos:

\section{CON PRONOMBRE:}

su estudio parece una actividad arqueológica escasamente atractiva, y se tiende a dejarlo recluido en las secciones de Español. LAZ 166

Si de lo que llevamos dicho pudiera deducirse alguna norma para nosotros, ésta sería: RAM 112

(...) cuando un esforzado de la forma, recibe un estilo de una gran tradición, y lejos de amenguarlo, lo devuelve acrecido, es un símbolo (...) LEZ 211

CON SUSTANTIVO:

Al ganar su cátedra de chibcha se comprometió a tener acabada la gramática de la lengua en cuatro años, (...) ALV 143

Con verbos ausentes en 19 textos:

(...) sobre todo los periodistas extranjeros, que no consideran terminado su trabajo mientras no se lleven el trofeo de una entrevista con él. GAR 169 (...) la madurez de una nación empieza cuando sus mejores hijos comprueban que las infinitas perfecciones con que en su infancia la creian dotada no son tales, (...) SAB 93

(...) un relato (...) en que la narración da hecho al niño el orden expositivo (...) GIL 112

El poeta intenta tan sólo descubrir por medio de vestidos, que estima adecuado, el lujo de la flor. LEZ 59

(...) artistas que no podemos llamar malogrados (...) RAM 124

(...) para que la publicidad televisada sacara acentuadas las mayúsculas

(...) VIC 42

Con adjetivos calificativos:

(...) la cultura de Occidente, donde el hombre ha tenido más clara y visible la imagen de la libertad. ZAM 103

(...) y encuentran extraordinariamente hermosas las canciones de moda; LAZ 191

(...) pero de este lado también (...) [el mundo hispánico] ha podido mantener vigente todo un repertorio humano (...) FUE 27

(...) esa mujer que lo había dejado y había dejado vacio el mundo para él, (...) BOR 41

En los cuadros siguientes se comparan las cifras obtenidas en 20 textos con los de 19 textos, según el orden de este último. 
VERBOS TRANSITIVOS CON ADJETIVO VERBAL SEGÚN LA NATURALEZA DEL RÉGIMEN

\begin{tabular}{lcccccc}
\hline & \multicolumn{3}{c}{19 textos } & \multicolumn{3}{c}{20 textos } \\
& + sustantivo & otros & total & + sustantivo & otros & total \\
\hline tener & 1 & 7 & 8 & 2 & 1 & 3 \\
dejar & 2 & 4 & 6 & 1 & 2 & 3 \\
ver & 3 & 1 & 4 & 1 & 0 & 1 \\
llevar & 2 & 1 & 3 & 0 & 1 & 1 \\
mantener & 2 & 1 & 3 & 0 & 0 & 0 \\
devolver & 0 & 1 & 1 & 0 & 1 & 1 \\
encontrar & 1 & 0 & 1 & 0 & 0 & 0 \\
traer & 0 & 1 & 1 & 0 & 0 & 0 \\
& & & & & & \\
considerar & 0 & 0 & 0 & 1 & 0 & 1 \\
creer & 0 & 0 & 0 & 0 & 1 & 1 \\
dar & 0 & 0 & 0 & 1 & 0 & 1 \\
estimar & 0 & 0 & 0 & 0 & 1 & 1 \\
juzgar & 0 & 0 & 0 & 0 & 1 & 1 \\
llamar & 0 & 0 & 0 & 0 & 1 & 1 \\
sacar & 0 & 0 & 0 & 1 & 0 & 1 \\
& & & & & & \\
total & 11 & 16 & 27 & 7 & 9 & 16 \\
\hline
\end{tabular}

VERBOS TRANSITIVOS CON ADJETIVO VERBAL Y SIN ÉL

\begin{tabular}{lrrrr}
\hline & $\begin{array}{c}19 \\
\text { textos }\end{array}$ & + A.V. & total & $\begin{array}{c}20 \text { textos } \\
+ \text { A.V. }\end{array}$ \\
\hline haber & 929 & 602 & 862 & 709 \\
tener & 314 & 8 & 168 & 3 \\
dejar & 76 & 6 & 70 & 3 \\
ver & 108 & 4 & 150 & 1 \\
llevar & 60 & 3 & 70 & 1 \\
mantener & 15 & 3 & 29 & 0 \\
devolver & 3 & 1 & 6 & 1 \\
encontrar & 59 & 1 & 73 & 0 \\
traer & 30 & 1 & 25 & 0 \\
& & & & \\
considerar & 50 & 0 & 39 & 1 \\
creer & 81 & 0 & 93 & 1 \\
dar & 145 & 0 & 152 & 1 \\
estimar & 15 & 0 & 5 & 1 \\
juzgar & 17 & 0 & 10 & 1 \\
llamar & 101 & 0 & 80 & 1 \\
sacar & 14 & 0 & 17 & 1 \\
\hline
\end{tabular}


FRECUENCIA RELATIVA POR VERBO DE EJEMPLOS CON ADJETIVO VERBAL

\begin{tabular}{|c|c|c|c|c|}
\hline & $\begin{array}{r}19 \text { textos } \\
+ \text { A.V. } \\
\text { F }\end{array}$ & $\%$ & $\begin{array}{r}20 \text { textos } \\
\text { +A.V. } \\
\text { F }\end{array}$ & $\%$ \\
\hline haber & 602 & 95,71 & 709 & 97,93 \\
\hline tener & 8 & 1,27 & 3 & 0,41 \\
\hline dejar & 6 & 0,95 & 3 & 0,41 \\
\hline ver & 4 & 0,64 & 1 & 0,14 \\
\hline llevar & 3 & 0,48 & 1 & 0,14 \\
\hline mantener & 3 & 0,48 & 0 & \\
\hline devolver & 1 & 0,16 & 1 & 0,14 \\
\hline encontrar & 1 & 0,16 & 0 & \\
\hline traer & 1 & 0,16 & 0 & \\
\hline considerar & 0 & & 1 & 0,14 \\
\hline creer & 0 & & 1 & 0,14 \\
\hline dar & 0 & & 1 & 0,14 \\
\hline estimar & 0 & & 1 & 0,14 \\
\hline juzgar & 0 & & 1 & 0,14 \\
\hline llamar & 0 & & 1 & 0,14 \\
\hline sacar & 0 & & 1 & 0,14 \\
\hline total & 630 & & 725 & \\
\hline
\end{tabular}

\subsection{EN COMPARACIÓN CON OTRAS CONSTRUCCIONES MARGINALES}

Si se amplía el campo de observación y se compara la frecuencia de los verbos transitivos asociados a un adjetivo verbal y un régimen directo en las condiciones antes descritas (43 ejemplos en 39 textos) con la de otras construcciones relativamente marginales, se ve que es inferior a la de los leísmos (115) ${ }^{17}$, los verbos conjugados pronominalmente con régimen y sin regente (79 ejemplos) ${ }^{18}$, el empleo de las formas en - $r a$ con valor de condicional (78) ${ }^{19}$ y los pronombres relativos compuestos con una forma demostrativa (64) ${ }^{20}$, pero es superior a la de los subjuntivos en $-r a$ con valor de pluscuamperfecto de indicativo (15) ${ }^{21}$, de los verbos conjugados prono-

17 Véase GE.EI, t II.6, Norma, libertad y probabilidad. Ocho soluciones del español: El leísmo. Una confusión opcional, en preparación.

${ }^{18}$ Véase el t. II. 2, Las formas pronominales del verbo y la pasiva, 1. ${ }^{\mathrm{a}}$ ed., § IV.1 (19 textos), 2. ${ }^{\text {a }}$ ed., $\S$ III. 3 (39 textos), de próxima aparición.

19 Véase GE.EI, t. I.2, Enseñanza: Índices y concordancias en la clase de gramática..., $\S 2$, La competencia entre el subjuntivo en -ra y el condicional.

${ }^{20}$ Véase GE.EI, t. I, Los pronombres demostrativos y relativos: De los esquemas teóricos $y$ de la realidad: Los pronombres demostrativos, $\S 2.3$.

${ }^{21}$ G. De Sterck, Registros y áreas. A propósito de la variación modal en el español de hoy, tesis doctoral. 
minalmente con un complemento agente $(11)^{22}$, del pronombre relativo, régimen directo, reduplicado (10) ${ }^{23}$, de le en lugar de les $(3)^{24}$, y de las formas pronominales del verbo, sin concordancia con el único grupo nominal que las acompaña $(2)^{25}$, por ejemplo.

\begin{tabular}{lrrrr}
\hline & $19 \mathrm{~T}$ & $20 \mathrm{~T}$ & $39 \mathrm{~T}$ & $0 / 0000$ \\
\hline Leísmos & 49 & 66 & 115 & 58 \\
Verbos pronominales + régimen, sin regente & 50 & 29 & 79 & 40 \\
-ra = -ría & 49 & 29 & 78 & 39 \\
Pronombre relativo + forma demostrativa & 32 & 32 & 64 & 32 \\
& & & & \\
Verbos transitivos + A.V. & 27 & 16 & 43 & 22 \\
& & & & \\
-ra $=$ indicativo & 5 & 10 & 15 & 8 \\
Verbos pronominales + por & 4 & 7 & 11 & 6 \\
Pronombres relativos, régimen directo, reduplicados & 8 & 2 & 10 & 5 \\
le $=$ les & 1 & 2 & 3 & 2 \\
Verbos pronominales sin concordancia & 2 & 0 & 2 & 1 \\
\hline
\end{tabular}

Cuantitativamente su posición en el uso es intermedia: entre una serie de construcciones más o menos generalizadas, gramaticalizadas y comúnmente empleadas y otras ocasionales, a menudo puestas en entredicho: detrás de la más discutida de las que se admiten, los pronombres relativos introducidos por una forma demostrativa y delante de la más aceptada de las discutidas.

La posición intermedia de los verbos transitivos inmediatamente seguidos de un adjetivo verbal en concordancia con el régimen directo, en la escala de frecuencia de algunas construcciones relativamente poco frecuentes en el mismo corpus refleja y explica la ambigüedad de la naturaleza gramatical de la asociación. Es insuficientemente frecuente para imponer un estatuto de fórmula gramaticalizada, pero es, sin embargo, lo bastante frecuente para que se piense que puede serlo. Puede tener vigencia, pero no se ha generalizado.

La confrontación muestra que la frecuencia de una construcción puede ser un índice de su gramaticalización en un estado de lengua determinado.

\footnotetext{
${ }^{22}$ Véase el t. II. 2, Las formas pronominales del verbo y la pasiva, $1 .^{\mathrm{a}}$ ed., $\S$ IV.2 (19 textos), 2. ${ }^{a}$ ed., $\S$ III. 2 (39 textos), de próxima aparición

${ }^{23}$ Véase GE.EI, t. I.5, Lengua escrita y habla culta en América y España: La reduplicación del pronombre relativo, régimen directo.

${ }^{24}$ Véase GE.EI, t. I.5, Lengua escrita y habla culta en América y España: 'le' por 'les'.

${ }^{25}$ Véanse los t. II.2, Las formas pronominales del verbo y la pasiva, $1 .^{\mathrm{a}}$ ed. § IV.1 (19 textos), 2. ${ }^{a}$ ed., $\S$ III. 1 (39 textos), de próxima aparición, y I.5, Lengua escrita y habla culta en América y España: Construcciones pronominales del verbo sin concordancia.
} 
$\mathrm{Al}$ contrario de los dictámenes que provienen de la competencia individual o de razonamientos teóricos, se trata de una medida que se deriva de la observación del uso, objetiva, precisa y graduada. Hay que señalar que no tiene por qué haber contradicciones entre la observación cuantificada, la intuición y la teoría.

Es evidente que el criterio de frecuencia - reducido aquí a su mínima expresión - podría ser refinado y que sería beneficioso reunir y confrontar un número mayor de construcciones marginales. Esto es posible si se recurre a corpus cerrados, reducidos e informatizados.

APÉNDICE N. ${ }^{0}$ 1.1. VeRBOS TRANSITIVOS CON ADJETIVO VERBAL EN 19 TEXTOS. REFERENCIAS

\begin{tabular}{|c|c|c|c|c|c|c|c|}
\hline ALO & & & & & GOY & & \\
\hline AYA & 179 & 406 & & & JIM & 46 & 644 \\
\hline BEN & 78 & & & & MAC & 91 & 214 \\
\hline CAR & 457 & & & & MAR & 117 & 165 \\
\hline CAS & & & & & ORT & 140 & 472 \\
\hline \multirow[t]{2}{*}{ CEL } & 502 & 675 & 771 & 804 & PER & 76 & \\
\hline & 859 & 952 & & & REY & & \\
\hline FER & & & & & SAL & & \\
\hline \multirow[t]{2}{*}{ GAL } & 86 & 124 & 176 & 267 & UNA & $304 * *$ & \\
\hline & $268^{*}$ & 353 & 419 & 702 & VAR & & \\
\hline GAO & & & & & & & \\
\hline
\end{tabular}

* Un verbo con cuatro adjetivos verbales.

** Un verbo con dos adjetivos verbales.

APÉNDICE N..$^{\circ} 1.2$. Verbos tRANSITIVOS CON ADJETIVO VERBAL EN 20 TEXTOS. REFERENCIAS

\begin{tabular}{lllllll}
\hline ALA & \multirow{2}{*}{143} & GUI & & & \\
ALV & 140 & HEN & & & \\
BAR & & LAZ & 166 & 191 & \\
BOR & & LEZ & 59 & 211 & \\
COR & & MAD & 4 & & \\
FUE & & PAZ & & & \\
GAI & & RAM & 71 & 112 & 124 \\
GAR & 169 & SAB & 93 & & \\
GIL & 112 & VIC & 42 & & \\
GOM & 60 & ZAM & 200 & & \\
\hline
\end{tabular}


APÉNDICE N..$^{\circ}$ 3. VERBos transitivos CON ADJETIVO VERBAL EN 39 TEXTOS Y 212 ARTíCULOS DE PERIÓDICO DE M. DE UNAMUNO

Si se comparan los corpus de 19 y 20 textos reunidos y compuestos de 39 autores diferentes - 197.880 ocurrencias - con un corpus homogéneo, en este caso 212 artículos de periódico de M. de Unamuno, de la misma época, 224.867 ocurrencias, que tiene pues un octavo más de extensión, se observan grandes similitudes y algunas diferencias. El número de verbos diferentes es ligeramente superior en Unamuno (20 en lugar de 15). Ocho verbos son comunes a ambas listas (dejar, tener, ver, llevar, creer, dar, encontrar y traer); la mitad aparece más de una vez en cada una de ellas (tener, dejar, ver, llevar en las dos listas; creer y dar en Unamuno); los tres verbos más frecuentes son los mismos (dejar, tener y ver). De 26 verbos, 18 son diferentes y la mayoría sólo aparece una vez. El corpus de Unamuno totaliza 70 ejemplos frente a 43 en 39 textos.

VERBOS TRANSITIVOS CON ADJETIVO VERBAL, EN 39 TEXTOS Y 212 ARTÍCULOS DE PERIÓdico DE Miguel de UNAMUNO

\begin{tabular}{|c|c|c|c|c|c|}
\hline $19+20$ textos & & & 212 artículos & & \\
\hline haber & 1.311 & $96,82 \%$ & haber & 1.254 & $94,71 \%$ \\
\hline dejar & 9 & & dejar & 25 & \\
\hline tener & 11 & & tener & 12 & \\
\hline ver & 5 & & ver & 9 & \\
\hline llevar & 4 & & creer & 3 & \\
\hline mantener & 3 & & dar & 3 & \\
\hline creer & 1 & & llevar & 3 & \\
\hline dar & 1 & & decir & 2 & \\
\hline devolver & 1 & & pedir & 2 & \\
\hline encontrar & 1 & & guardar & 1 & \\
\hline estimar & 1 & & encontrar & 1 & \\
\hline juzgar & 1 & & hacer & 1 & \\
\hline llamar & 1 & & hincar & 1 & \\
\hline sacar & 1 & & poner & 1 & \\
\hline \multirow[t]{6}{*}{ traer } & 1 & & representar & 1 & \\
\hline & & & saber & 1 & \\
\hline & & & sentir & 1 & \\
\hline & & & tomar & 1 & \\
\hline & & & traer & 1 & \\
\hline & & & transcribir & 1 & \\
\hline total & 1.354 & & total & 1.324 & \\
\hline
\end{tabular}


La confrontación pone de manifiesto que muchos verbos diferentes, variables de un autor a otro, pueden estar asociados a un adjetivo verbal y también que hay verbos comúnmente preferidos; por orden de frecuencia: dejar, tener, ver, llevar.

Unamuno muestra clara preferencia por dejar. De los 25 ejemplos, sin embargo, 17 están combinados con el adjetivo verbal dicho; se encuentra también escrito (tres veces), así como sentado y grabado (cada uno una vez).

Y esto que Quevedo dejó dicho que "No hay cosa (...) 07.02.34/9

Esto corrobora que los ejemplos en 39 textos (LEZ 676, 953, RAM 71 y CEL 772,) no son casualidad y que se trata efectivamente de una expresión lexicalizada.

Se confirma que hay autores más apegados que otros a la construcción, como Gallegos y Cela en el corpus de 39 textos. Sin embargo, no deja de ser cierto que, en comparación con haber (1.254 ejemplos), los 70 ejemplos con otros 20 verbos en Unamuno son insuficientes para poder concluir que hay instrumentalidad (auxiliaridad).

Finalmente, sea cual sea la cifra absoluta de ejemplos, la diferencia de frecuencia relativa de los verbos transitivos asociados a un adjetivo verbal, entre ellos, y la de los verbos intransitivos en Unamuno ${ }^{26}$ es tan importante como la que media entre las dos series en la prosa informativa. Mientras que estar, el verbo más frecuente después de ser, constituye el 20 por ciento de los ejemplos en la serie intransitiva (el 23 por ciento en 19 textos), dejar que ocupa el mismo rango en la serie transitiva, apenas si alcanza el dos por ciento (1,27 por ciento en los 19 textos); etc.

VERBOS TRANSITIVOS E INTRANSITIVOS CON ADJETIVO VERBAL EN 212 ARTíCULos DE PERIÓdico De Miguel de Unamuno

\begin{tabular}{|c|c|c|c|c|c|}
\hline \multicolumn{4}{|c|}{$\%$} & \multicolumn{2}{|r|}{$\%$} \\
\hline haber & 1.254 & 94,71 & $\operatorname{ser}(\mathrm{se})$ & 145 & 34,04 \\
\hline dejar & 25 & 1,89 & estar(se) & 87 & 20,42 \\
\hline tener & 12 & & $\operatorname{ir}(s e)$ & 23 & \\
\hline ver & 9 & & quedar(se) & 20 & \\
\hline creer & 3 & & sentirse & 20 & \\
\hline$d a r$ & 3 & & creerse & 11 & \\
\hline
\end{tabular}

${ }^{26}$ Véase GE.EI, t. II.3, La noción de auxiliaridad, § II.2. 


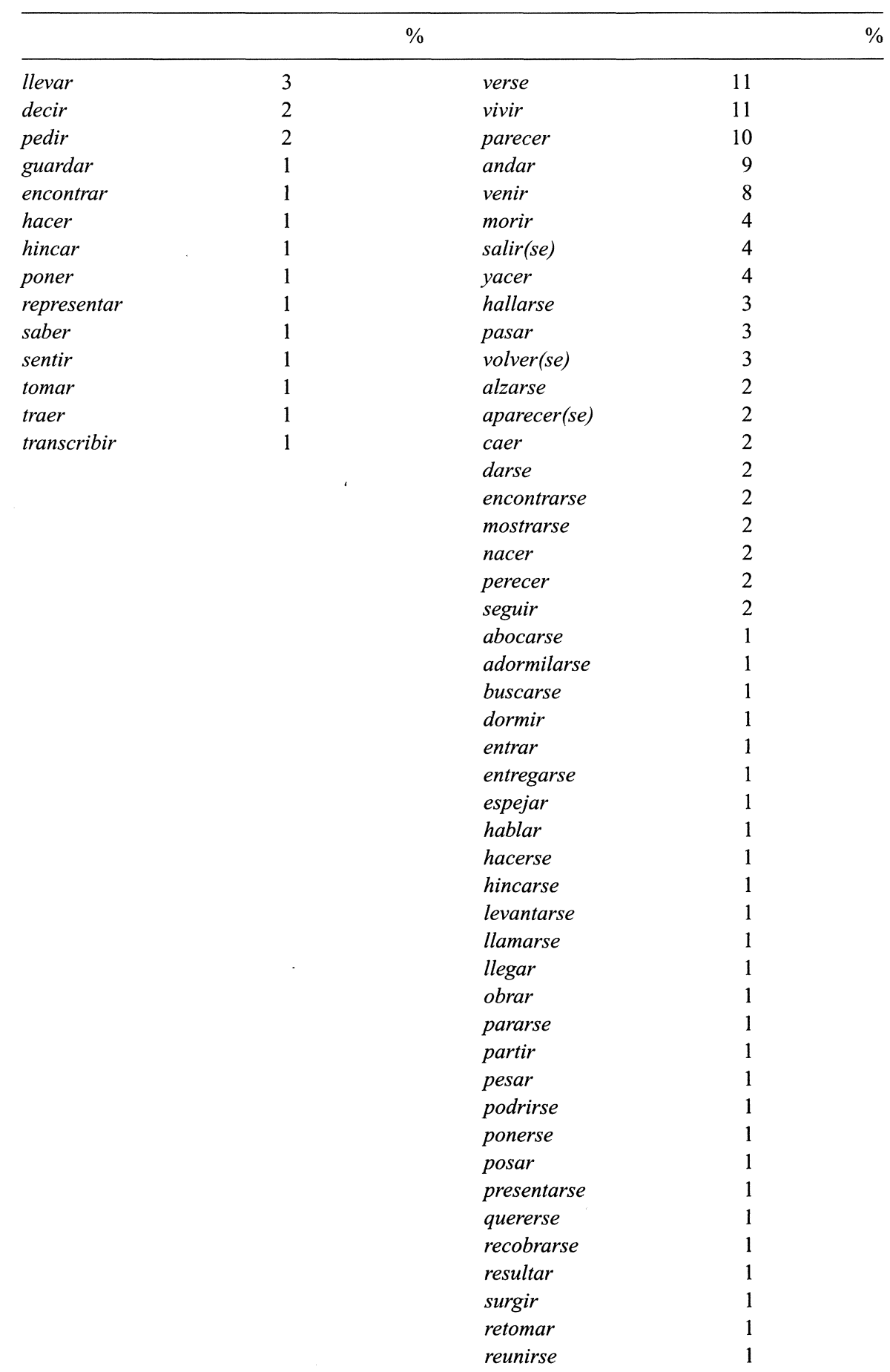


RFE, LXXVIII, 1998

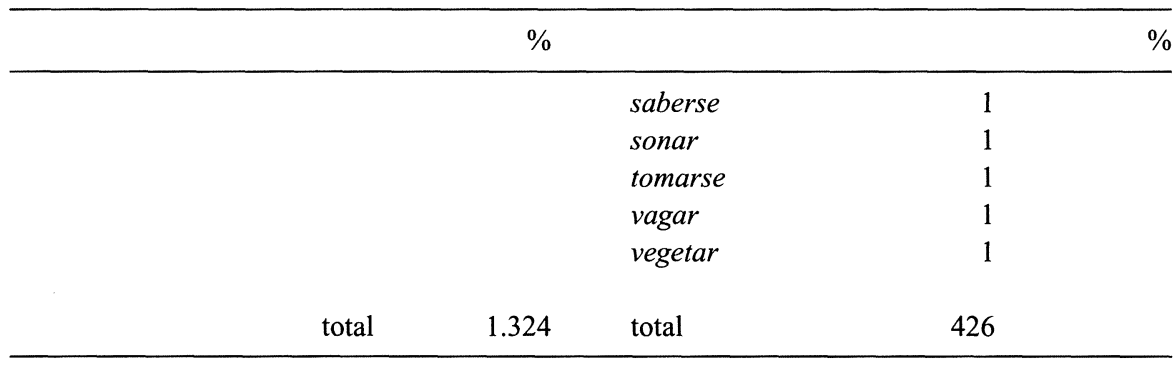

